\title{
The Effectiveness Analysis of Different Procedure of Nursing Coordination for Phacoemulsification Combined with Intraocular Lens Implantation Surgery
}

\author{
Lihuan Hou*, Aizhu Qiu, Xiaojuan He, Daoting Chen, Xiaohong Huang \\ Operating Room of the First Hospital Affiliated of Jinan University, Guangzhou, China
}

Email address:

lihuanhou02@126.com (Lihuan Hou)

${ }^{*}$ Corresponding author

\section{To cite this article:}

Lihuan Hou, Aizhu Qiu, Xiaojuan He, Daoting Chen, Xiaohong Huang. The Effectiveness Analysis of Different Procedure of Nursing Coordination for Phacoemulsification Combined with Intraocular Lens Implantation Surgery. American Journal of Nursing Science. Vol. 6, No. 2, 2017, pp. 131-134. doi: 10.11648/j.ajns.20170602.17

Received: December 22, 2016; Accepted: January 18, 2017; Published: February 24, 2017

\begin{abstract}
To analysis the effectiveness of different procedure of nursing coordination for phacoemulsification combined with intraocular lens implantation (IOL) surgery. Forty patients who received phacoemulsification combined with intraocular lens implantation surgery from Feb, 2014 to Sep, 2015 in the department of Ophthalmology in the First Affiliated Hospital of Jinan University were recruited for analysis. Patients were divided into two groups randomly: 20 patients with usual nursing procedure (the control group) and 20 patients in improved nursing procedure (the experimental group). The following parameters were collected: intraoperative swelling pain of the eye, operation time, complications of conjunctiva and cornea 1 and 7 days after the surgery, the position of IOL, intraocular pressure, visual acuity and the satisfactory level of surgeon and patients. The significant differences between the two groups were analysis by SPSS 19.0. Compared with the control group, the improved nursing coordination procedure showed less intraoperative swelling pain of the eye, shorter operation time, reduced corneal edema rate 1 day after the surgery, greater satisfaction of both the surgeons and patients. The improved nursing coordination procedure suggests success and safety of this combined surgery by shortening the operation time, reducing postoperative complications and improving the satisfaction of doctors and patients.
\end{abstract}

Keywords: High Myopia, Phacoemulsification Cataract, Intraocular Lens Implantation, Nursing Coordination Procedure

\section{Introduction}

High myopia, defined as an eye axial length greater than 26 $\mathrm{mm}$ and spherical equivalent -6.00 diopers (D) [1], affects the entire eye [2]. There are relationships between myopia and cataract $[3,4]$. In highly myopic patients, cataracts occur more frequently and develop more rapidly [5-7]. According to the literature, high myopia related cataract (HMC) is typically characterized by dark nuclei rather than other types of lens opacity $[8,9]$. High myopia related cataract will lead to severe low vision or even blindness, greatly impacting the quality of patients' living life [10]. Phacoemulsification combined with intraocular lens implantation is the prior option to cure the disease $[11,12]$. The therapeutic effects of this combined surgery depends on the nursing pattern and procedure. Many groups have been exploring the coordinating procedure for phacoemulsification and formed the normal nursing procedure [13]. However, there is still lacking nursing protocols which aim at the high myopia patients with phacoemulsification. Thus, we collected 4o patients with high myopia cataract underwent phacoemulsification and applied two different nursing coordination procedure during the operation, to provide evidences for formulating surgical coordination protocol of these patients.

\section{Methods}

\subsection{Subject}

Forty patients who received phacoemulsification combined with intraocular lens implantation surgery from Feb, 2014 to Sep, 2015 in the department of Ophthalmology in the First 
Affiliated Hospital of Jinan University were recruited. Patients were randomly chosen for the usual coordination procedure (the control group) or the improved coordination procedure (the experimental group).

\subsection{Inclusion Criteria}

Consent agreed patients of age between 40 to 85 years old; Emery classification of grade II to III; eye axis $\geq 26.00 \mathrm{~mm}$; refraction $\geq-6.00 \mathrm{D}$; with no corneal disease, glaucoma, retinal detachment, retinal hemorrhage and eye surgery history.

\subsection{Exclusion Criteria}

Patients with posterior capsule rupture or vitreous prolapse during the operation or those who cannot followed-up on time.

\subsection{Coordination Procedure}

Here, we used two coordination procedure during the operation: (1) The usual protocol: Routinely set the ocular perfusion height to $76 \mathrm{~cm}$ (the perfusion height of the operation eye equals to the height of the perfusate bottle), set the perfusion pressure to $300 \mathrm{mmHg}$; adjust the height and pressure according to the surgeon during the operation, nursing passively; (2) The improve protocol: nurses adjust the perfusion height according to the length of eye axis: perfusion height $10 \mathrm{~cm}$ lower $(76 \mathrm{~cm}$ to $66 \mathrm{~cm}$ ) when eye axis between $26.00 \mathrm{~mm}$ and $28.00 \mathrm{~mm} ; 20 \mathrm{~cm}$ lower when eye axis between $28.00 \mathrm{~mm}$ and $30.00 \mathrm{~mm} ; 30 \mathrm{~cm}$ lower when eye axis over $30.00 \mathrm{~mm}$; negative pressure is $250 \mathrm{mmHg}$; perfusion $5 \mathrm{~cm}$ lower after the implantation; nursing actively and predictively.

\subsection{Recording Parameters}

The following parameters were collected: intraoperative swelling pain of the eye, operation time, complications of conjunctiva and cornea 1 and 7 days after the surgery, the position of IOL, intraocular pressure, visual acuity; the satisfactory level of surgeon and patients by questionnaire.

\subsection{Statistical Analysis}

Excel database was setup, SPSS 19.00 was used to analyses the data. Binomial categorical variables using the four-grid test or probability calculation; numerical variables using t-test; multinomial categorical variables using the Wilcoxon rank sum test. $\mathrm{P}<0.05$ means statistical significant differences.

\section{Results}

We analyzed the sex, age, vision, eye axis, eye pressure, anterior chamber depth, lens nucleus grade, corneal endothelial cell density, history of diabetes, history of hypertension, phacoemulsification time, phacoemulsification energy. All these parameters showed no significant differences $(\mathrm{P}>0.05$, Table 1). Then analyzed the intraoperative swelling pain of the eye (Table 2), operation time (Table 3), complications of conjunctiva (Table 4) and cornea (Table 5) 1 and 7 days after the surgery, the position of IOL, intraocular pressure (Table 6) and visual acuity (Table 7); the satisfactory level of surgeon and patients (Table 8). These indicators showed significant differences between the two groups. In both groups, the position of IOL were normal, the aqueous humor was clear, vitreous and fundus showed no abnormal.

Table 1. The general data.

\begin{tabular}{|c|c|c|c|c|c|}
\hline & & Experimental group & Control group & $t \chi^{2}$ & $P$ \\
\hline Sex & $\begin{array}{l}\text { Male } \\
\text { Female }\end{array}$ & $\begin{array}{l}8 \\
12\end{array}$ & $\begin{array}{l}11 \\
9\end{array}$ & 0.90 & 0.34 \\
\hline Age & $\begin{array}{l}\bar{x} \\
\mathrm{~S} \\
\mathrm{n}\end{array}$ & $\begin{array}{l}63.30 \\
12.96 \\
20\end{array}$ & $\begin{array}{l}61.85 \\
14.37 \\
20\end{array}$ & 0.34 & 0.74 \\
\hline Vision & $\begin{array}{l}\bar{x} \\
\mathrm{~S} \\
\mathrm{n}\end{array}$ & $\begin{array}{l}0.27 \\
0.20 \\
20\end{array}$ & $\begin{array}{l}0.30 \\
0.24 \\
20\end{array}$ & 0.38 & 0.71 \\
\hline Eye axis & $\begin{array}{l}\bar{x} \\
\mathrm{~S} \\
\mathrm{n}\end{array}$ & $\begin{array}{l}27.76 \\
2.11 \\
20\end{array}$ & $\begin{array}{l}27.89 \\
1.79 \\
20\end{array}$ & 0.22 & 0.83 \\
\hline Eye pressure & $\begin{array}{l}\bar{x} \\
\mathrm{~S} \\
\mathrm{n}\end{array}$ & $\begin{array}{l}13.65 \\
2.21 \\
20\end{array}$ & $\begin{array}{l}14.95 \\
2.35 \\
20\end{array}$ & 1.80 & 0.08 \\
\hline Anterior chamber depth & $\begin{array}{l}\bar{x} \\
\mathrm{~S} \\
\mathrm{n}\end{array}$ & $\begin{array}{l}3.16 \\
0.23 \\
20\end{array}$ & $\begin{array}{l}3.16 \\
0.19 \\
20\end{array}$ & 0.05 & 0.96 \\
\hline Lens nucleus grade & $\begin{array}{l}\text { II } \\
\text { III }\end{array}$ & $\begin{array}{l}4 \\
16\end{array}$ & $\begin{array}{l}4 \\
16\end{array}$ & 0.00 & 1.00 \\
\hline Corneal endothelial cell density & $\begin{array}{l}\bar{x} \\
\mathrm{~S} \\
\mathrm{n}\end{array}$ & $\begin{array}{l}2133.62 \\
352.79 \\
20\end{array}$ & $\begin{array}{l}2345.63 \\
455.50 \\
20\end{array}$ & 1.65 & 0.11 \\
\hline History of diabetes & $\begin{array}{l}\text { yes } \\
\text { no }\end{array}$ & $\begin{array}{l}2 \\
18\end{array}$ & $\begin{array}{l}1 \\
19\end{array}$ & 0.36 & 0.55 \\
\hline History of hypertension & $\begin{array}{l}\text { yes } \\
\text { no }\end{array}$ & $\begin{array}{l}6 \\
14\end{array}$ & $\begin{array}{l}4 \\
16\end{array}$ & 0.53 & 0.47 \\
\hline Phacoemulsification energy & $\bar{x}$ & 0.03 & 0.03 & 0.95 & 0.35 \\
\hline
\end{tabular}




\begin{tabular}{llllll}
\hline & & Experimental group & Control group & $\boldsymbol{t}_{\chi^{2}}$ & $\boldsymbol{P}$ \\
\hline & $\mathrm{S}$ & 0.02 & 0.03 & & \\
& $\mathrm{n}$ & 20 & 0 & & \\
& $\bar{x}$ & 0.30 & 0.43 & 1.48 & 0.15 \\
Phacoemulsification time & $\mathrm{S}$ & 0.16 & 0.37 & 20 & \\
& $\mathrm{n}$ & 20 & & \\
\hline
\end{tabular}

Table 2. The swelling pain.

\begin{tabular}{llll}
\hline & \multicolumn{2}{l}{ Pain of the operation eye } & \multirow{2}{*}{ Total } \\
\cline { 2 - 3 } & Yes & No & \\
\hline Experimental group & 2 & 18 & 20 \\
Control group & 15 & 5 & 20 \\
Total & 17 & 23 & 40 \\
& $\chi^{2}=17.29, P=0.00$ & \\
\hline
\end{tabular}

Table 3. The operation time.

\begin{tabular}{llll}
\hline & $\mathbf{N}$ & $\bar{x}$ & $\mathbf{S}$ \\
\hline Experimental group & 20 & 14.00 & 2.58 \\
Control group & 20 & 19.10 & 3.09 \\
$t=5.67, P=0.00$ & & & \\
\hline
\end{tabular}

Table 4. Postoperative conjunctival hyperemia.

\begin{tabular}{llllll}
\hline & \multirow{2}{*}{$\mathbf{N}$} & $\mathbf{1 d}$ & \multicolumn{3}{l}{$\mathbf{7 d}$} \\
\cline { 3 - 6 } & & Yes & No & Yes & No \\
\hline Experimental group & 20 & 2 & 18 & 1 & 19 \\
Control group & 20 & 6 & 14 & 1 & 19 \\
$\chi^{2}$ & & 2.50 & & 1.00 & \\
$P$ & & 0.11 & & 0.76 & \\
\hline
\end{tabular}

Table 5. Corneal edema.

\begin{tabular}{llllll}
\hline & \multirow{2}{*}{$\mathbf{N}$} & $\mathbf{1 d}$ & \multicolumn{3}{l}{$\mathbf{7 d}$} \\
\cline { 3 - 6 } & & Yes & No & Yes & No \\
\hline Experimental group & 20 & 3 & 17 & 1 & 19 \\
Control group & 20 & 12 & 8 & 0 & 20 \\
$\chi^{2}$ & & 8.64 & & 1.00 & \\
$P$ & & 0.00 & & 5.00 & \\
\hline
\end{tabular}

Table 6. Eye pressure.

\begin{tabular}{llllll}
\hline & \multirow{2}{*}{$\mathbf{N}$} & $\mathbf{1 d}$ & & $\mathbf{7 d}$ & \\
\cline { 3 - 6 } & & $\bar{x}$ & $\mathbf{S}$ & $\bar{x}$ & $\mathbf{S}$ \\
\hline Experimental group & 20 & 18.00 & 5.85 & 15.40 & 3.03 \\
Control group & 20 & 17.30 & 3.48 & 15.50 & 3.09 \\
$t$ & & 0.46 & & 0.10 & \\
$P$ & & 0.65 & & 0.92 & \\
\hline
\end{tabular}

Table 7. Vision acuity.

\begin{tabular}{|c|c|c|c|c|c|}
\hline & \multirow{2}{*}{$\mathbf{N}$} & \multirow{2}{*}{$\frac{1 \mathrm{~d}}{\bar{x}}$} & \multicolumn{3}{|c|}{$7 d$} \\
\hline & & & $\mathbf{S}$ & $\bar{x}$ & $\mathbf{S}$ \\
\hline Experimental group & 20 & 0.70 & 0.22 & 0.78 & 0.28 \\
\hline Control group & 20 & 0.67 & 0.27 & 0.74 & 0.28 \\
\hline$t$ & & 0.29 & & 0.46 & \\
\hline$P$ & & 0.77 & & 0.65 & \\
\hline
\end{tabular}

Table 8. The satisfaction level of surgeon and patients.

\begin{tabular}{lllllll}
\hline & \multicolumn{2}{l}{ Of surgeon } & & Of patients & & Total \\
\cline { 2 - 7 } & Fair & Satisfied & Very satisficed & Fair & Satisfied & Very satisficed \\
\hline Experimental group & 0 & 2 & 18 & 0 & 4 & 16 \\
Control group & 1 & 13 & 6 & 3 & 13 & 4 \\
Total & 1 & 15 & 24 & 3 & 17 & 20 \\
& $W=289$, & & $P=0.00$ & $W=284$, & $P=0.00$ & 40 \\
\end{tabular}

\section{Discussion}

Myopia, the most common human eye disorder, affects more than $80 \%$ of young people in Asian countries [14]. High myopia defines as eyes with spherical equivalent refractive error of at least $-6.00 \mathrm{D}$ and axial length of at least $26.00 \mathrm{~mm}$, which often accompanies with cataract [15]. In China, the prevalence of high myopia is about $1.3 \%$ to $26 \%$ [16]. Surgeries on high myopia cataract are difficult due to the pathological changes of the eye structure, bearing higher risk rate than normal cataract. The outcome of the surgery depends not only on the proper surgical method and the skills of surgeons, but also much on the doctor nurse coordination during the operation. Some researcher suggested that nursing on patients with phacoemulsification is different from normal cataract, precise coordination procedure should be designed according to the surgical features and nursing difficulties [17]. The importance of postoperative nursing skills with phacoemulsification has been raised [18], however, there is still no report on the nursing coordination during the operation of phacoemulsification combined with intraocular lens implantation surgery.

High myopia with cataract show the character of scleral wall thinning and softening, decreased compressive tension. If the perfusion height stays unchanged as normal cataract before the operation, eye pressure would temporarily raise up due to the high perfusion pressure during the operation. This will lead to the pain and discomfort of patients. We innovatively adjust the coordination procedure as to lower the perfusion height according to the actual situation, thus perfectly controlled eye pressure and relieved eye pain. Reduce the height of cataract perfusion will avoid deep anterior chamber of patients with long eye axis, can prevent anterior chamber surging due to decreased force on lentil, thus can greatly reduce the operation difficulty, the risk, the operation time, reduce the rate of postoperative corneal edema and finally increased the satisfaction of both surgeon and patient. Our improved nurse-doctor coordination procedure on phacoemulsification combined with intraocular lens 
implantation surgery worth to learn from.

\section{Conclusion}

By analyzing the effectiveness of different procedure of nursing coordination for phacoemulsification combined with intraocular lens implantation (IOL) surgery, the improved nursing coordination procedure suggests success and safety of this combined surgery by shortening the operation time, reducing postoperative complications and improving the satisfaction of doctors and patients.

\section{References}

[1] Akal, A., T. Goncu, S. S. Cakmak, I. Yuvaci, M. Atas, S. Demircan, and O. F. Yilmaz, Evaluation of early results of quick-chop phacoemulsification in the patients with high myopic cataract. Int J Ophthalmol, 2014, 7 (5): 828-31.

[2] Saw, S. M., G. Gazzard, E. C. Shih-Yen, and W. H. Chua, Myopia and associated pathological complications. Ophthalmic Physiol Opt, 2005, 25 (5): 381-91.

[3] Perkins, E. S., Cataract: refractive error, diabetes, and morphology. Br J Ophthalmol, 1984, 68 (5): 293-7.

[4] Weale, R., A note on a possible relation between refraction and a disposition for senile nuclear cataract. Br J Ophthalmol, 1980 64 (5): 311-4.

[5] Kaufman, B. J. and J. Sugar, Discrete nuclear sclerosis in young patients with myopia. Arch Ophthalmol, 1996, 114 (10): 1178-80.

[6] Fernandez-Buenaga, R., J. L. Alio, A. L. Perez-Ardoy, A. Larrosa-Quesada, L. Pinilla-Cortes, R. Barraquer, J. L. Alio, 2nd, and F. J. Munoz-Negrete, Late in-the-bag intraocular lens dislocation requiring explantation: risk factors and outcomes. Eye (Lond), 2013, 27 (7): 795-801; quiz 802.

[7] Younan, C., P. Mitchell, R. G. Cumming, E. Rochtchina, and J. J. Wang, Myopia and incident cataract and cataract surgery: the blue mountains eye study. Invest Ophthalmol Vis Sci, 2002, 43 (12): 3625-32.
[8] Praveen, M. R., G. D. Shah, A. R. Vasavada, P. G. Mehta, C. Gilbert, and G. Bhagat, A study to explore the risk factors for the early onset of cataract in India. Eye (Lond), 2010, 24 (4): 686-94.

[9] Zhu, X. J., P. Zhou, K. K. Zhang, J. Yang, Y. Luo, and Y. Lu, Epigenetic regulation of alphaA-crystallin in high myopia-induced dark nuclear cataract. PLoS One, 2013, 8 (12): e81900.

[10] Ieong, A., G. S. Rubin, and B. D. Allan, Quality of life in high myopia: implantable Collamer lens implantation versus contact lens wear. Ophthalmology, 2009, 116 (2): 275-80.

[11] Kamiya, K., K. Shimizu, A. Igarashi, D. Aizawa, and T. Ikeda, Clinical outcomes and patient satisfaction after Visian Implantable Collamer Lens removal and phacoemulsification with intraocular lens implantation in eyes with induced cataract. Eye (Lond), 2010, 24 (2): 304-9.

[12] Khafizova, G. F. and E. N. Verigo, [Optimization of elastic intraocular lens implantation technology in the phacoemulsification of different types of cataract]. Vestn Oftalmol, 2007, 123 (6): 26-9.

[13] Lau, K. Y. and Z. C. Chan, Crisis management after incorrect intraocular lens insertion. J Cataract Refract Surg, 2012, 38 (8): 1499-501.

[14] Leo, S. W. and T. L. Young, An evidence-based update on myopia and interventions to retard its progression. $J A A P O S$, 2011, 15 (2): 181-9.

[15] Yang, J., S. Zhou, J. Gu, M. Guo, H. Xia, and Y. Liu, UPR Activation and the Down-Regulation of alpha-Crystallin in Human High Myopia-Related Cataract Lens Epithelium. PLoS One, 2015, 10 (9): e0137582.

[16] Liang, Y. B., T. Y. Wong, L. P. Sun, Q. S. Tao, J. J. Wang, X. H. Yang, Y. Xiong, N. L. Wang, and D. S. Friedman, Refractive errors in a rural Chinese adult population the Handan eye study. Ophthalmology, 2009, 116 (11): 2119-27.

[17] Mutonen, N. V., [Methods for reducing traumatism of the posterior corneal epithelium during ultrasound phacoemulsification]. Vestn Oftalmol, 2008, 124 (2): 53-6.

[18] Chevallier, M. and N. Weber, [The nurse dealing with phacoemulsification]. Soins Chir, 1995 (169): 16-20. 